\title{
Russell-Silver Syndrome
}

National Cancer Institute

\section{Source}

National Cancer Institute. Russell-Silver Syndrome. NCI Thesaurus. Code C85068.

A rare inherited growth disorder characterized by growth retardation, feeding difficulties, failure to thrive, facial abnormalities and asymmetry of limbs. Camptodactyly or clinodactyly may be present. 